\title{
Bees and Aerosols
}

\section{B. GROBETY ${ }^{1 *}$, V. LEUENBERGER ${ }^{2}$, C. NEURURER ${ }^{3}$}

${ }^{1}$ Dep. of Geosiences, Univ. of Fribourg, CH-1700, Switzerland (correspondence: bernard.grobety@unifr.ch

${ }^{2}$ Dep. of Geosciences, Univ. of Fribourg, CH-1700, Switzerland, vivian.leuenberger@unifr.ch

${ }^{3}$ Dep. of Geosciences, Univ. of Fribourg, CH-1700,

Switzerland, christoph.neururer@unifr.ch

An unconventional method to get an overlook on aerosol particles deposited in the environment is to analyze particles attached on the bodies of honey bees (Apis mellifera, L.)[1]. By collecting nectar and pollen, other particles accumulate on the bee's surface. Honey bees were sampled around beehives located in four different background settings (urban, rural, close to a highway, close to a shooting range). The dried and carbon coated bees were analysed manually by Scanning Electron Microscopy (SEM) and Energy Dispersive Spectroscopy (EDS). The morphology and chemistry of the particles were used for a rough source apportionment. All bees had in a size range of 1 to $100 \mu \mathrm{m}$ attached to their body. Due to carbon coating and the bee's body composition, organic particles like pollen or carbon particles (soot) are difficult to analyze chemically, but in most cases can be distinguished based on morphology. In addition to pollen and soil-derived (dust) particles, which were always present, the particle population contained site specific components. Bees from the beehive close to the highway clearly showed an increase of non-biological carbon particles, most likely traffic-derived soot. Heavy metal rich particles containing $\mathrm{Pb}, \mathrm{Ba}, \mathrm{Cu}, \mathrm{Hg}, \mathrm{Zn}$ and $\mathrm{Sn}$, typical for the composition of gunshot residue, were found on bees from the beehive close to the shooting range. The results show, that the analysis of particles found on the surface of bees are an efficient tool to monitor the predominant sources of aerosol in the vicinity of beehives.

[1] Negri, I. et al. 2015. PLoS ONE, doi: journal.pone.0132491. 